\title{
Complementation of the Magnaporthe grisea $\triangle c p k A$ Mutation by the Blumeria graminis PKA-c Gene: Functional Genetic Analysis of an Obligate Plant Pathogen
}

\author{
Lene Bindslev, ${ }^{1}$ Michael J. Kershaw, ${ }^{2}$ Nicholas J. Talbot, ${ }^{2}$ and Richard P. Oliver ${ }^{3}$ \\ ${ }^{1}$ Department of Physiology, Carlsberg Laboratory, Gl. Carlsbergvej 10, 2500 Valby, Denmark; ${ }^{2}$ School of \\ Biological Sciences, University of Exeter, Washington Singer Laboratories, Perry Road, Exeter EX4 4PS, \\ U.K.; ${ }^{3}$ Australian Centre for Necrotrophic Fungal Pathogens, Murdoch University, Perth 6150, Western \\ Australia \\ Submitted 1 May 2001; Accepted 5 July 2001.
}

\begin{abstract}
Obligate plant-pathogenic fungi have proved extremely difficult to characterize with molecular genetics because they cannot be cultured away from host plants and only can be manipulated experimentally in limited circumstances. Previously, in order to characterize signal transduction processes during infection-related development of the powdery mildew fungus Blumeria graminis (syn. Erysiphe graminis) f. sp. hordei, we described a gene similar to the catalytic subunit of cyclic AMP-dependent protein kinase A (here renamed Bkal). Functional characterization of this gene has been achieved by expression in a $\triangle c p k A$ mutant of the nonobligate pathogen Magnaporthe grisea. This nonpathogenic $M$. grisea $\Delta c p k A$ mutant displays delayed and incomplete appressorium development, suggesting a role for PKA-c in the signal transduction processes that control the maturation of infection cells. Transformation of the $\triangle c p k A$ mutant with the mildew Bkal open reading frame, controlled by the $M$. grisea MPG1 promoter, restored pathogenicity and appressorium maturation kinetics. The results provide, to our knowledge, the first functional genetic analysis of pathogenicity in an obligate pathogen and highlight the remarkable conservation of signaling components regulating infectionrelated development in pathogenic fungi.
\end{abstract}

Molecular genetic analysis of phytopathogenic fungi is revealing the presence of conserved signal transduction pathways that regulate infection-related development and the production of plant disease symptoms (Lev et al. 1999; Xu and Hamer 1996). These studies have been restricted to species that are tractable to genetic manipulation, leaving the vast majority of pathogenic species, including many significant crop disease-causing fungi, unexplored and poorly understood. Among these species are important pathogenic fungi that live as obligate pathogens. These species, including powdery mil-

Corresponding author: R. P. Oliver

E-mail: roliver@central.murdoch.edu.au dew and rust fungi, cannot be cultured or maintained away from living plants and, therefore, present a very significant challenge to biological investigation. Obligate pathogens are arguably the most specialized phytopathogenic species; they are able to survive and proliferate only in living plant tissue; cause very limited systemic damage to plants; often have very restricted host ranges and conform to the gene-for-gene hypothesis; and produce persistent, polycyclic, and damaging infections (Giese et al. 1997).

Blumeria (syn. Erysiphe) graminis f. sp. hordei is the causal organism of barley (Hordeum vulgare) powdery mildew disease and is a prime example of an obligate pathogen that has been difficult to characterize at the molecular genetic level, possessing fascinating developmental biology. Losses resulting from this disease can be as high as $25 \%$ of the barley harvest (Parry 1990), ranking the fungus as one of the most serious diseases of temperate cereals. B. graminis infections begin when asexual spores (conidia) germinate and penetrate the host epidermis by undergoing a well-described developmental pathway (Kunoh 1982). Within 15 to $30 \mathrm{~min}$ of landing on the host surface, B. graminis conidia develop a primary germ tube. Surface features are then perceived by the germ tube which, if appropriate, lead to the emergence of an appressorial germ tube after 4 to $6 \mathrm{~h}$. The appressorial germ tube then elongates, undergoes cell division, and forms an appressorium. The penetration of the host cell by the appressorium is believed to involve cell wall-degrading enzymes and generation of turgor pressure (Francis et al. 1996; Frick and Wolf 1994). The process is markedly different from that of most appressorium-forming fungi because it does not require free water and occurs on dry leaves. The complexity of appressorium morphogenesis and its dependence on the perception of the environment implies involvement of specialized signal transduction pathways.

So far, molecular genetic analysis of B. graminis has been limited by its obligate nature, but the advent of genome-level analysis has provided new means by which its biology can be explored. Recently, a large number of $B$. graminis expressed sequence tag (EST) sequences has been generated (Thomas et 
al. 2001) from germinating B. graminis conidia, and classification of these genes by means of similarity has revealed some that are likely to encode signal transduction components. The presence of these expressed genes is consistent with the operation of particular signaling pathways, although proving the involvement of individual genes and determining the details of their interactions requires the development of novel methods and approaches. One of the B. graminis ESTs shows sequence similarity to the cyclic AMP (cAMP)-dependent protein kinase A catalytic subunit (PKA-c; here renamed Bkal) (Hall et al. 1999), suggesting a role for a cAMP-dependent signaling pathway in B. graminis appressorium development.

Enzymatic determination of PKA activity changes in germinating conidia, measurement of cAMP concentration fluxes, and the effects of spore treatment with cAMP and analogs have together provided evidence that the cAMP-signaling pathway plays a key role in initiating germ tube emergence in $B$. graminis (Kinane et al. 2000). cAMP levels and PKA-c activity have been shown to have a biphasic pattern during conidial germination. cAMP accumulates after $15 \mathrm{~min}$ and $4 \mathrm{~h}$, prior to the emergence of the primary and appressorial germ tubes, respectively.

The cAMP signal transduction pathway has been implicated in developmental programs of a small number of nonobligate fungal pathogens, including Ustilago maydis, the corn smut fungus, in which mutants defective in PKA-c fail to produce symptomatic galls in host plants and are defective in cytokinesis (Gold et al. 1994). In Colletotrichum trifolii, PKA-c may be involved in germination and appressorial formation but more likely is involved in host penetration (Yang and Dickman 1997, 1999a, 1999b). The organism in which most studies have been carried out is the rice blast fungus Magnaporthe grisea, an ascomycete fungus pathogenic on rice and many other cereals, including barley (Kang et al. 1999). M. grisea germ tubes form appressoria that penetrate the host cell with mechanical force (de Jong et al. 1997; Howard et al. 1991). cAMP is required for appressorium morphogenesis because $\Delta m a c 1$ mutants, which are deficient in adenylate cyclase activity, fail to make appressoria and are nonpathogenic (Choi and Dean 1997). This mutation is unstable in certain strains as a result of bypass suppressor mutations in the SUM1 gene encoding the regulatory subunit of PKA (PKA-r) (Adachi and Hamer 1998). Furthermore, the addition of cAMP also can induce appressoria to form on normally noninductive hydrophilic surfaces or even from hyphal tips (Lee and Dean 1993). Targeted disruption of the $C P K A$ gene encoding the PKA-c subunit gives rise to mutants that show a significant delay in appressorium formation, forming small nonfunctional cells (Mitchell and Dean 1995; Xu et al. 1997). The inability of $\triangle c p k A$ appressoria to bring about plant infection may be related to their abnormal carbohydrate and lipid mobilization in these cells and the consequent effects on turgor generation (Thines et al. 2000).

In this report, we describe the results of expressing the $B$. graminis gene Bkal in a $\Delta c p k A$ mutant of $M$. grisea. Expression of $B k a l$ complemented the dysfunction in appressorium morphogenesis and partially restored its virulence phenotype. This provides, to our knowledge, the first functional gene analysis of $B$. graminis and shows that a gene from an obligate pathogenic species is able to act as a pathogenicity determinant in $M$. grisea.

\section{RESULTS}

\section{Functional complementation \\ of a $M$. grisea $\triangle c p k A$ mutant.}

In order to express the B. graminis Bkal gene in $M$. grisea, two transformation vectors were constructed (Fig. 1A and B). Both constructs utilized a $1.28-\mathrm{kb}$ Pst $\mathrm{I}-\mathrm{Nco}$ I fragment of the $M P G 1$ promoter, which has been shown previously to lead to high gene expression during conidial germination and appressorium development (Kershaw et al. 1998; Talbot et al. 1993). The MPG1 promoter fragment was subcloned upstream of a 1.57-kb full-length genomic Bkal sequence in pLB2 and of a 1.4-kb Bkal cDNA sequence in pLB3. Both constructs were made in pCB1625 (Sweigard et al. 1998), comprising the bar
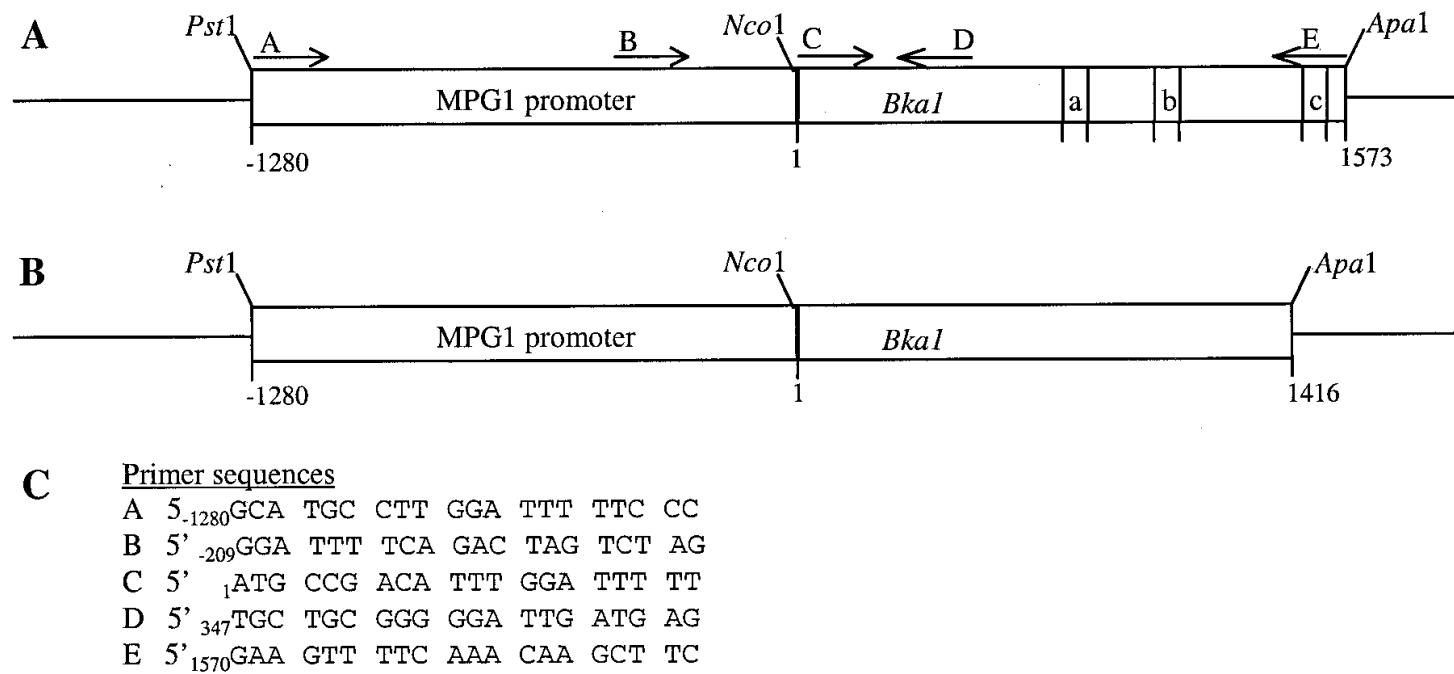

Fig. 1. Constructs used for transformation of Magnaporthe grisea. A, Plasmid pLB2 containing the genomic Bkal controlled by the MPG1 promoter. B, Plasmid pLB3 containing Bkal without introns, which also are controlled by the MPG1 promoter. C, Primer sequences, shown in $\mathbf{A}$, indicated by arrows A to E. 
selectable marker, which bestows bialaphos resistance in $M$. grisea, and were introduced into $M$. grisea strain DF51 (Xu et al. 1997), a $\triangle c p k A: H P H$ transformant derived from parent strain 4091-5-8 (Valent et al. 1986) with standard DNA-mediated transformation (Talbot et al. 1993). After 6 days, bialaphosresistant colonies were picked and transferred to new Bastacontaining plates. A total of 30 and 28 positive transformants was generated with $\mathrm{pLB} 2$ and $\mathrm{pLB} 3$, respectively. A number

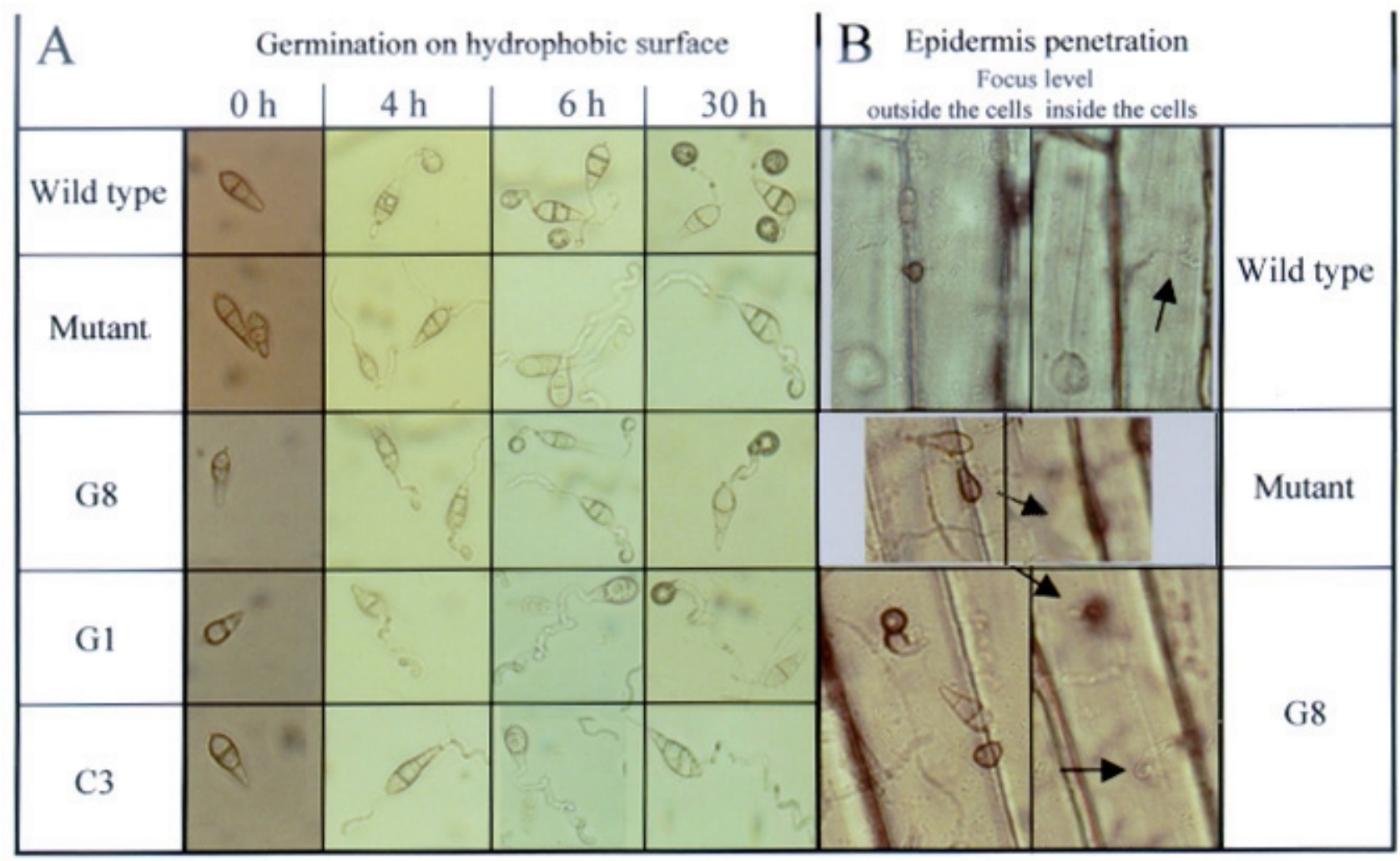

Fig. 2. Microscopic analysis of Magnaporthe grisea conidia. A, Germination of conidia on hydrophobic, plastic coverslips. Conidia were germinated in water droplets and photographed after $0,4,6$, and $30 \mathrm{~h}$. B, Appressorial penetration of leek epidermis $30 \mathrm{~h}$ after inoculation. Arrows indicate penetration hyphae (wild type and G8) or where the hyphae is expected (mutant).
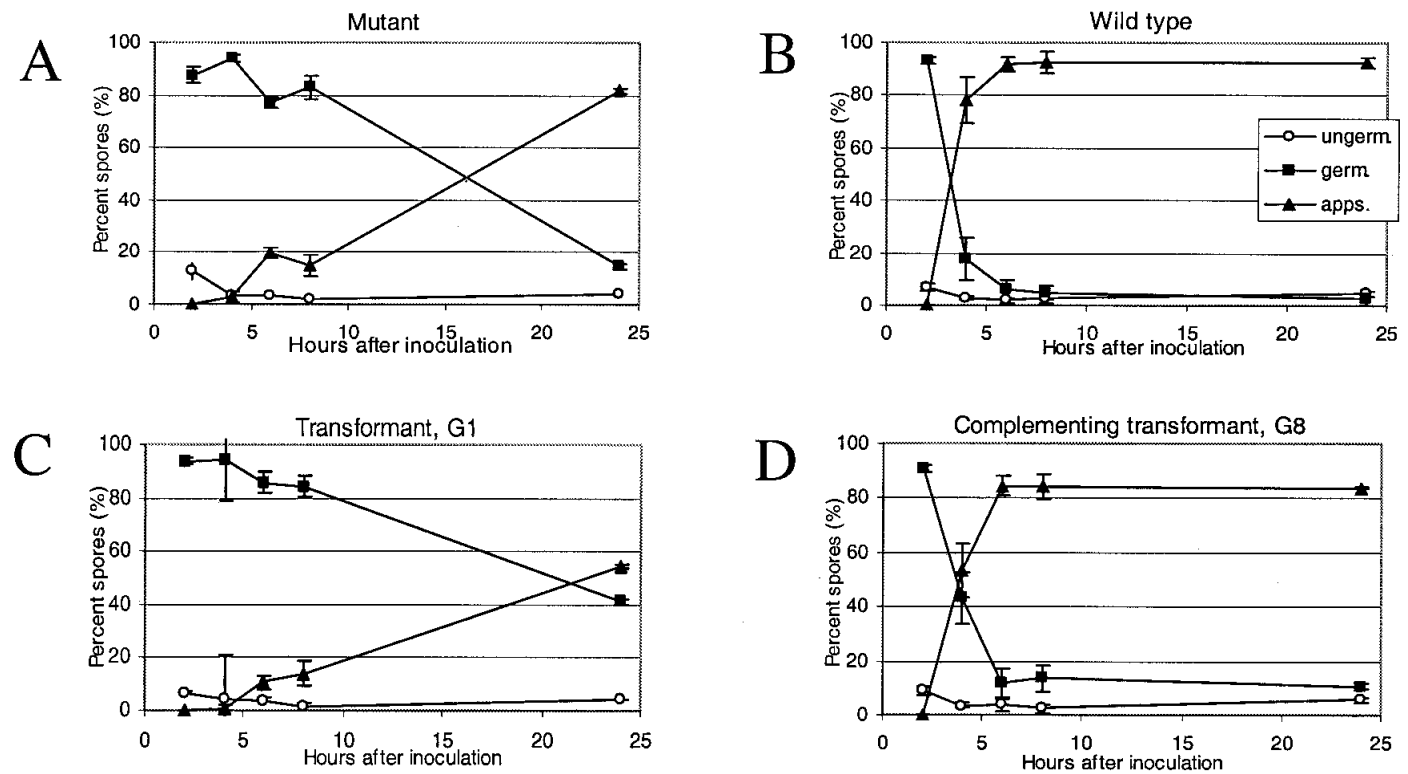

Fig. 3. Germination of Magnaporthe grisea conidia. Spores $\left(2 \times 10^{3}\right)$ of each strain were placed on plastic coverslips and observed 2, 4, 6, 8, and $24 \mathrm{~h}$ after inoculation. The number of spores that remained ungerminated (ungerm), germinated (germ), and developed appressoria (apps) was counted. A, Mutant DF51. B, Wild-type 4091-5-8. C, Transformant G1. D, Complementing transformant G8. Error bars indicate 95\% confidence interval. 
of control strains transformed with pCB1625 also were recovered. The transformants were all stable, as judged by their ability to grow on bialaphos plates after 7 to 8 weeks of subculturing on normal complete medium (CM) plates.

\section{Infection-related development} of MPG1(p)::Bka1::Bar:: $\triangle$ cpkA ::HPH transformants.

The $\triangle c p k A$ mutants of $M$. grisea are delayed substantially in germ tube differentiation and produce small, nonfunctional appressoria (Mitchell and Dean 1995; Xu et al. 1997). In order to determine whether these phenotypes could be complemented by expression of the B. graminis Bkal gene, conidia of bialaphos-resistant transformants were allowed to germinate on hydrophobic plastic surfaces. Microscopic analysis showed that the timing and extent of germination and appressorium formation varied between the strains selected (Fig. 2A). Three bialaphos transformants, G1 and G8 (made with the genomic DNA vector pLB2) and C3 (made with the cDNA vector pLB3), were selected and examined. After $4 \mathrm{~h}$, hooking of the wild-type (4091-5-8) germ tube began, and appressorium formation started shortly thereafter (Fig. 2A). At 6 h, most appres- soria were fully formed. Conidia of the $\triangle c p k A$ mutant DF51 also had germinated by $4 \mathrm{~h}$, but after $6 \mathrm{~h}$, the germ tubes had only just started to hook, and it was not until after $30 \mathrm{~h}$ that all appressoria had formed. Conidial development in G8 was similar to wild-type strain 4091-5-8, whereas G1 developed similar to the $\triangle c p k A$ mutant (Fig. 2A). Another transformant, $\mathrm{C} 3$, had very slow and aberrant conidial development. It may be that the vector integrated into an important gene in this transformant.

To determine whether these morphological differences were reproducible, quantitative microscopic analysis was performed. Conidia $(2,000)$ of each transformant were tracked during germination under appressorium-inducing conditions (Fig. 3). Wild-type strain 4091-5-8 (Fig. 3B) and transformant G8 (Fig. 3D) formed the maximum number of appressoria after $6 \mathrm{~h}$, and $93 \%$ of the wild-type spores formed appressoria compared with $83 \%$ of those from G8. Development in the $\triangle c p k A \mathrm{mu}-$ tant DF51 (Fig. 3A) and transformant G1 (Fig. 3C) was much slower. After $25 \mathrm{~h}$, only $81 \%$ of the $\triangle c p k A$ spores had formed appressoria in the mutant and as few as $58 \%$ in the G1 transformant.

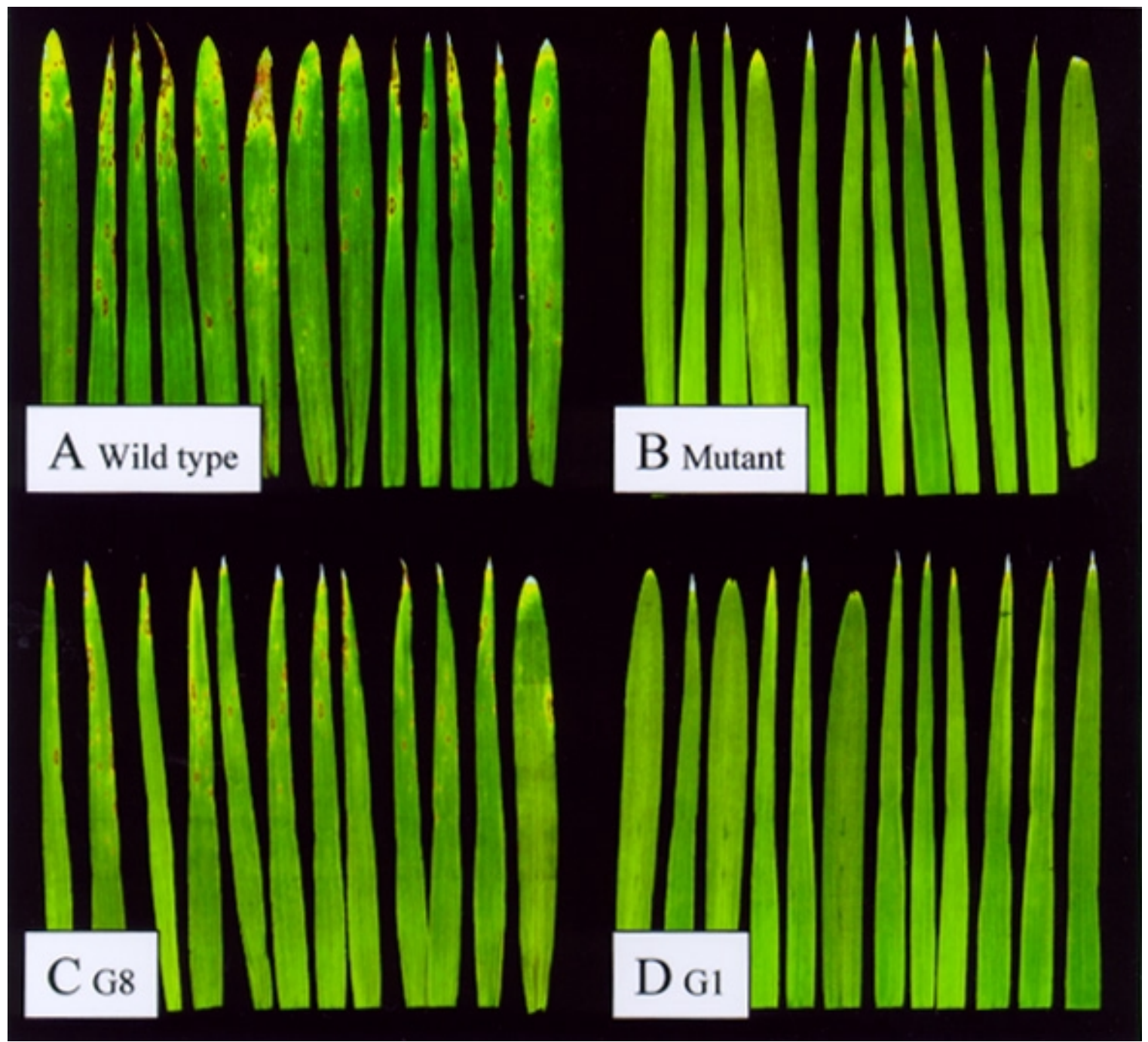

Fig. 4. Pathogenicity assay of Magnaporthe grisea spores on barley leaves. Spores were sprayed onto intact plants and photographed 5 days later. The wild type and the G8 transformant infected the leaves, whereas the mutant and the G1 transformant did not form lesions. 


\section{Appressorium-mediated cuticle penetration.}

The $\triangle c p k A$ mutation results in appressoria that are nonfunctional and incapable of penetrating plant cuticles (Xu et al. 1997). The ability of appressoria to penetrate plant cuticles was, therefore, assessed on leek epidermis in an adaptation of the methods described by Chida and Sisler (1987) (Fig. 2B). Conidia were inoculated onto the epidermis in a drop of water and analyzed microscopically $30 \mathrm{~h}$ later. Wild-type strain 4091-5-8 and transformant G8 produced penetration pegs that had breached the cuticle and proliferated in the epidermis, and penetration hyphae could be seen clearly within the cells (Fig. 2B). In contrast, the $\triangle c p k A$ mutant DF51 had not produced penetration pegs, even after $30 \mathrm{~h}$.

\section{Pathogenicity of $M$. grisea transformants.}

Deficiencies in appressorium development and function mean that $\triangle c p k A$ mutants are completely nonpathogenic on barley and rice (Mitchell and Dean 1995; Xu et al. 1997). In order to determine whether expression of Bkal could complement this phenotype, pathogenicity to susceptible barley cultivar Golden Promise was assessed. Spores from all of the transformants, $\Delta c p k A$ mutant DF51, and wild-type 4091-5-8 were sprayed onto 1-week-old seedlings, and the disease was allowed to progress for 5 days. The leaves were then examined for lesions (Fig. 4). As expected, the wild-type strain infected at a high frequency and mutant DF51 produced no lesions. G1 also produced no symptoms. Transformant G8, containing vector pLB2, infected barley, and the lesions were normal in appearance and size (Fig. 4). G8 produced 4.6 \pm 2.2 lesions per leaf, whereas the wild type produced $10.2 \pm 1.2$ (Table 1). Fungal mycelium emanating from the disease lesions of the G8 and wild-type infections was tested for resistance to Basta (discussed below). Mycelium from the G8 lesions was Basta resistant, whereas the mycelium from the wild-type infections was sensitive, as expected.

The in vitro growth rate and sporulation of the wild type, mutant DF51, and transformants G8 and G1 also were measured (Table 1). For both parameters, the mutant was significantly impaired compared with the wild type. The wild type grew $7.3 \pm$ $0.3 \mathrm{~mm}$ per day, whereas the mutant, G8, and G1 all grew 6.6 to $6.8 \pm 0.3 \mathrm{~mm}$ per day. This difference is statistically significant $(P<0.001)$. The production of conidia varied as well. The wild type produced $5.3 \times 10^{7}$ spores per plate and the mutant produced $2.3 \times 10^{7}$ spores per plate. G8 $\left(3.7 \times 10^{7}\right)$ and $\mathrm{G} 1\left(1.5 \times 10^{7}\right)$ produced similar numbers of spores as the mutant. A Mann-Whitney $U$ test showed that the production of wild-type spores was significantly higher than in other strains

Table 1. Phenotypic analysis of Magnaporthe grisea strains, including the wild type, mutant, G8, and $\mathrm{G}^{\mathrm{a}}$

\begin{tabular}{|c|c|c|c|c|}
\hline train & Wild type & Mutant & G8 & G1 \\
\hline $\begin{array}{l}\text { athogenicity } \\
\text { Srowth rate } \\
\text { spore production }\end{array}$ & $\begin{array}{r}10.2 \pm 1.2 \\
7.3 \pm 0.3 \\
5.3 \pm 0.6\end{array}$ & $\begin{array}{l}0.0 \pm 0.0^{* *} \\
6.6 \pm 0.3^{*} \\
2.3 \pm 0.6^{* *}\end{array}$ & $\begin{array}{l}4.6 \pm 2.2 * * \\
6.8 \pm 0.2^{*} \\
3.7 \pm 0.6^{* *}\end{array}$ & $\begin{array}{l}0.0 \pm 0.0^{* *} \\
6.7 \pm 0.3^{*} \\
1.5 \pm 0.7^{* *}\end{array}$ \\
\hline $\begin{array}{l}\text { and } * * \text { Indica } \\
\text { and } P<0.001 \text {, } \\
\text { growth rate an } \\
\text { production (Fow } \\
\text { Lesions per plan }\end{array}$ & ighty & $\begin{array}{l}\text { rence } \\
\text { he Kru } \\
\text { itney }\end{array}$ & ,il & at \\
\hline
\end{tabular}

$(P<0.05)$. It also showed that G8 produced significantly more spores than $\mathrm{G} 1$ and the mutant $(P<0.001)$. Together, the expression of Bkal in transformant G8 appears to have resulted in at least partial complementation of these secondary $\triangle c p k A$ mutant phenotypes.

\section{MPG1(p)::PKA-c is intact and transcribed only in the active transformant.}

The complementation of the mutant phenotype in transformant G8 suggests that the introduced $B k a l$ gene encoded PKA activity. It was surprising, however, that only 1 out of 58 transformants tested displayed complementation. Polymerase chain reaction (PCR) and Southern blotting were therefore used to determine whether intact copies of the transgene had integrated into the $M$. grisea genome. Genomic DNA was recovered from G8 and five inactive transformants (three cDNA and two genomic DNA transformants, selected randomly), and PCR was performed with primers from within the Bkal and MPGl sequences (Fig. 5). Primers $\mathrm{C}$ and $\mathrm{E}$ from Bkal (Fig. 1) amplified bands of $1,570 \mathrm{bp}$ were taken from genomic clone transformants G8, G3, and G1 (Fig. 5, lanes 4 to 6, respectively) and of 1,415 bp were taken from cDNA transformants $\mathrm{C} 1, \mathrm{C} 2$, and $\mathrm{C} 3$ (Fig. 5, lanes 7 to 9, respectively). These amplicons were of identical size to those produced from the source plasmids (Fig. 5, lanes 10 and 11). The predicted 2.7or 2.9-kb bands corresponding to $M P G 1(p):: B k a l$ were shown, by Southern blotting, to be absent in strains C1, C2, C3, and G3, but present in G1 and G8 (blot not shown). To discriminate the integration events in G1 and G8, PCR with additional primers was performed. Primers A and D and B and D produced the expected size amplicons in G1 and G8. In con-

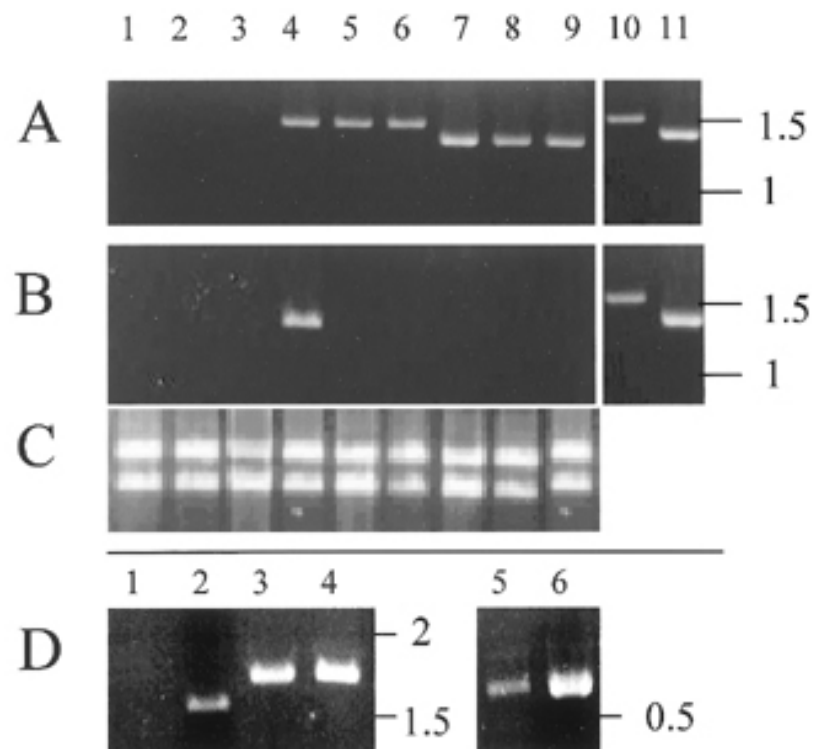

Fig. 5. Polymerase chain reaction (PCR) and reverse-transcription (RT)PCR assays of the presence and expression of Bkal in Magnaporthe grisea (primer locations in Fig. 1). A to C, Lanes: 1, wild type; 2, mutant; 3, empty vector; 4, G8; 5, G3; 6, G1; 7, C3; 8, C2; 9, C1; 10, genomic DNA plasmid control; and 11, cDNA plasmid control. D, Lanes 1, 3, and 5, G1; and 2, 4, and 6, G8. A, PCR with primers C and E. B, RT-PCR with primers C and E. C, RNA used for RT-PCR in B. D, PCR with primers A to D (lanes 1 and 2), B to E (lanes 3 and 4), and B to D (lanes 5 and 6). 
trast, primers $\mathrm{B}$ and $\mathrm{E}$ produced a fragment only from the active transformant G8 (Fig. 5D). Together, the PCR and hybridization show that only G8 contained the intact $M P G 1(p):: B k a l$ construct.

To determine whether the MPG1(p)1::Bkal construct led to expression of Bkal in M. grisea, total RNA was extracted from mycelia grown in liquid $\mathrm{CM}$ for 2 days at $30^{\circ} \mathrm{C}$. Reverse-transcription (RT)-PCR was performed on the transformants, mutant, and wild type (Fig. 5B and C) with primers $\mathrm{C}$ and E. A 1,415-bp band was amplified only from strain G8 (Fig. 5, lane 4). This suggests that no or very low expression was achieved in the nonpathogenic transformants and is likely to explain their failure to complement. Furthermore, the size of the RT-PCR amplicon from G8 is consistent with correct splicing of the $B$. graminis genomic sequence by the $M$. grisea transcription apparatus.

\section{DISCUSSION}

Functional complementation of the $\triangle c p k A$ mutation from $M$. grisea with the Bkal gene from $B$. graminis restored pathogenicity to the mutant. This observation, combined with the sequence of the gene, implies that Bkal encodes an active PKA-c, which is sufficient to restore this activity to a $M$. grisea null mutant. The Bkal gene is thus a functional homolog of the $c p k A$ gene.

The $\triangle c p k A$ mutant is nonpathogenic to healthy leaves, because appressoria fail to penetrate the host cells (Mitchell and Dean 1995; Xu et al. 1997). In this study, we have shown that a transformant strain, G8, expressing the B. graminis Bkal gene under control of high-level, appressorium-specific promoter $M P G l(p)$, could substantially complement the nonpathogenic phenotypes associated with $\triangle c p k A$ strains. Spores from this transformant were able to induce lesions on the host leaves at approximately half the frequency of an isogenic $M$. grisea wild-type strain, whereas the mutant was completely nonpathogenic (Fig. 4 and Table 1). The frequency of appressorium development on glass was almost as high in G8 as it was in the wild type and approximately $20 \mathrm{~h}$ faster than the mutant (Xu et al. 1997). The mutant also was impaired in growth rate and sporulation, and the phenotypes were partially restored in the pathogenic G8 transformant.

The failure of G8 to fully restore all of the mutant phenotypes associated with $\triangle c p k A$ mutations was intriguing. The most likely explanation for these deficiencies is that the promoter is inappropriate in timing or strength. A signaling component, such as $C P K A$, is likely to be required at a relatively low but sustained level throughout fungal growth and development (Thevelein 1994). The promoter used for expression of the Bkal transgene was from MPGl, which encodes a hydrophobin in $M$. grisea (Talbot et al. 1993). This promoter was chosen because of its high-level expression during germination and appressorium development (Kershaw et al. 1998). The repression of MPG1 during growth in rich medium may explain the inability of the Bkal transgene to restore wild-type growth kinetics to transformant G8. Alternatively, the partial complementation may be because of amino acid sequence differences between the PKA-c from B. graminis and $M$. grisea, which plausibly could limit the effectiveness of the introduced protein. We also cannot exclude the possibility of pleiotropic effects being caused by the random insertion of transgenes in the $M$. grisea genome.
We chose to transform $M$. grisea with genomic and cDNA sequences. The pathogenic transformant (G8) was transformed with genomic DNA, and the expressed Bkal transcript was confirmed by RT-PCR to be the spliced version of the gene. Thus, it seems that $M$. grisea is able to splice this B. graminis gene. The ability to test genomic sequences from $B$. graminis for complementation in $M$. grisea greatly increases the experimental utility of the protocol.

A noteworthy aspect of this study is that only 1 out of 58 transformants expressed the Bkal gene. Each of the five inactive transformants that were examined in detail had truncated versions of $\mathrm{Bkal}$ and/or multiple integration events. Only one transformant expressed the gene, as determined by functional assays and confirmed by RT-PCR. This low frequency of complementation may reflect the toxicity of highlevel expression of the Bkal gene. It may be that transgene expression was counter-selected during the transformation procedure. In considering how to adapt this procedure for the routine analysis of B. graminis genes, it would thus be desirable to produce vectors that express heterologous genes under control of a range of promoters or a controllable promoter.

\section{MATERIALS AND METHODS}

\section{Strains and media.}

M. grisea wild-type (4091-5-8) and mutant (DF51) strains were cultured at $24^{\circ} \mathrm{C}$ in a cycle of 18 -h light-6-h dark. The fungi were grown in 19-mm petri dishes on CM plates containing $15 \mu \mathrm{l}$ per $\mathrm{ml}$ of Basta (150 mg per ml; Aventis, Lyon, France) (Talbot et al. 1993). Mutant DF51 (Xu et al. 1997) was generated by replacing the EagI-EcoRV fragment of the PKA-c gene with the HPH gene in 4091-5-8 (Valent et al. 1986).

\section{Vectors for transformation of $M$. grisea.}

An expression vector with the promoter for MPG1 (M. grisea) and Bkal was constructed. The MPGl promoter was moved from pNJ190 (NcoI-PstI digest) into expression vector pCB1265 (containing the Basta resistance gene). PCR with primers forward (1), TAT ACC $A_{1} T G G_{N c o I} \mathrm{CG}$ ACA TTT

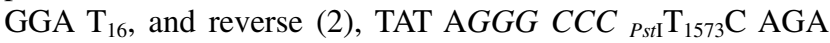
AGT TTT CAA ACA $\mathrm{AG}_{1555}$, was performed with 25 cycles for $30 \mathrm{~s}$ at $94^{\circ} \mathrm{C}, 1 \mathrm{~min}$ at $54^{\circ} \mathrm{C}$, and $1.5 \mathrm{~min}$ at $72^{\circ} \mathrm{C}$. In addition, $10 \mathrm{U}$ of Taq-polymerase (Promega, Bie and Berntsen, Rodovre, Denmark), $1 \times$ buffer (Promega, Bie and Berntsen), $2.5 \mathrm{mM} \mathrm{MgCl}_{2}$, and 1 pmol of each primer, all in a $20-\mu \mathrm{l} \mathrm{vol-}$ ume, were used on genomic DNA and cDNA of the PKA-c gene from B. graminis (Hall et al. 1999). The fragments were digested with NcoI and ApaI and inserted into pCB1265 containing the MPG1 promoter. To confirm that the gene was in frame and intact, the recombinants were sequenced by Dideoxy terminator sequencing (Sanger et al. 1977) with a PRISM BigDye terminator kit (PE Biosystems, Naerum, Denmark), and the reactions were analyzed on an ABI Prism 377 DNA sequencer (Perkin-Elmer, Allerod, Denmark). DNA restriction and agarose gel fractionation were performed according to standard methods (Sambrook et al. 1989).

\section{Fungal transformation.}

Protoplast isolation was carried out as described by Talbot et al. (1993). Protoplasts were made from mutant strain DF51. 
Protoplasts were resuspended in STC buffer (0.6 M sucrose; $10 \mathrm{mM}$ Tris-HCL, $\mathrm{pH} 7.5$; and $10 \mathrm{mM} \mathrm{CaCl}_{2}$ ), adjusted to a concentration of $5 \times 10^{6}$ per $\mathrm{ml}$, and cooled slowly to $-70^{\circ} \mathrm{C}$ for storage. An aliquot of $150 \mu \mathrm{l}$ of protoplasts and $2 \mu \mathrm{g}$ of DNA was used for each transformation. Protoplasts were regenerated overnight at $24^{\circ} \mathrm{C}$ in the dark and then overlaid with media containing Basta at a concentration of $15 \mu \mathrm{g}$ of media per ml. Basta-resistant transformants were recovered after 7 days and subcultured to $\mathrm{CM}$ plates supplemented with $15 \mu \mathrm{g}$ of Basta per ml. Transformants were stored at $-20^{\circ} \mathrm{C}$ on sterile filter paper disks that were kept dry in 50-ml Falcon tubes with silica gel. The transformants were named with a $G$ when genomic DNA was used for the transformation and a $\mathrm{C}$ when cDNA was used.

\section{Pathogenicity assay.}

M. grisea spores were collected in sterile water from 6day-old plates. The spores were counted, and the concentration was adjusted to $1 \times 10^{6}$ per ml. Conidial suspension $(3 \mathrm{ml})$ was sprayed onto 1-week-old 'Golden Promise' barley seedlings (SCRI, Invergowrie, Scotland) in a pot containing 15 to 20 plants. The seedlings have two leaves at this stage. After 5 days, the number of lesions per plant was scored. A total of 80 plants was infected for each $M$. grisea strain, and the experiment was repeated once. Thirty lesions from the G8 and wild-type infections were excised from the leaves with a sterile razor blade and transferred to $\mathrm{CM}$ plates. When a colony formed, it was subcultured to CM plates containing Basta.

\section{Growth rate and spore production.}

The growth rate of $M$. grisea strains was measured on plates as the radial increase in millimeter per day of the fungus. The measurements started 3 days after subculturing and ended 9 days later, when the fungus had grown to the edge of the petri dish. Twenty plates were used per strain, and the experiment was repeated three times. Harvesting spores in $3 \mathrm{ml}$ of water from 6-day-old plates and counting the spores in a fraction of the water determined the spore production. Twenty plates were used per strain, and the experiment was repeated twice.

\section{Conidia germination.}

A sample of the spores collected for the pathogenicity test was used for the germination assays. Conidial concentration was adjusted to $2 \times 10^{4}$ per $\mathrm{ml}$, and $90-\mu \mathrm{l}$ drops were placed on plastic coverslips (Menzel-Glaser, Braunscheig, Germany) or epidermis from leek leaves floating on distilled water. The spores were germinated for 0 to $30 \mathrm{~h}$ in a moist chamber at $24^{\circ} \mathrm{C}$. Germinating spores were counted and photographed with 160T film (Kodak, Rochester, NY, U.S.A.) at 400× magnification with an Axioplan light microscope (Carl Zeiss, Thornwood, NY, U.S.A.). Two hundred spores on plastic slides were counted per strain, and the experiment was carried out three times. A total of 200 spores was examined on the leek epidermis.

\section{RNA and DNA extraction.}

A modified cetyltrimethylammonium bromide extraction procedure was used to extract genomic DNA from resting conidia (Hall et al. 1999), and Trizol reagent was used to extract RNA from resting conidia (GIBCO-BRL, Taastrup, Den- mark), following the manufacturer's protocol. An additional separation step was introduced (spin at $12,000 \times g$ for $10 \mathrm{~min}$ at $4{ }^{\circ} \mathrm{C}$ ) before the addition of chloroform to remove highmolecular DNA.

\section{PCR and RT-PCR.}

To examine integration events, PCR was performed using the primers listed in Figure 1C. PCR reactions were run, as reported above. For the creation of first-strand cDNA, $5 \mu \mathrm{g}$ of total RNA was incubated at $70^{\circ} \mathrm{C}$ for 10 min with primer E, cooled on ice, and then incubated at $42^{\circ} \mathrm{C}$ for 50 min with $1 \mathrm{mM}$ deoxynucleoside triphosphate, $5 \mathrm{mM}$ dithiothreitol, $1 \times$ buffer (GIBCO-BRL), and $200 \mathrm{U}$ of SuperScript II (GIBCOBRL), followed by $15 \mathrm{~min}$ at $70^{\circ} \mathrm{C}$. To amplify cDNA, $2 \mu \mathrm{l}$ of the $20-\mu \mathrm{l}$ RT-PCR mix was used in a $50-\mu \mathrm{l}$ PCR reaction with the primers $\mathrm{C}$ and $\mathrm{E}$.

\section{ACKNOWLEDGMENTS}

This work was supported by the EU TMR Cerepat project FMRXCT98-0241. Members of both laboratories are thanked for discussions.

\section{LITERATURE CITED}

Adachi, K., and Hamer, J. E. 1998. Divergent cAMP signalling pathways regulate growth and pathogenesis in the rice blast fungus Magnaporthe grisea. Plant Cell 10:1361-1273.

Choi, G. H., and Dean, R. A. 1997. The adenylate cyclase gene MAC1 of Magnaporthe grisea controls appressorium formation ad other aspects of growth and development. Plant Cell 9:1973-1983.

Chida, T., and Sisler, H. D. 1987. Restoration of appressorial penetration ability by melanin precursors in Pyricularia oryzae treated with antipenetrants and in melanin-deficient mutants. J. Pestic. Sci. 12:49-55.

de Jong, J. C., McCormack, B. J., Smirnoff, N., and Talbot, N. J. 1997. Glycerol generates turgor in rice blast. Nature 389:244-245.

Fowler, J., Cohen, L., and Jarvis, P. 1998. Practical Statistics for Field Biology, 2nd ed. John Wiley \& Sons, New York.

Francis, S. A., Dewey, F. M., and Gurr, S. J. 1996. The role of cutinase in germling development and infection by Erysiphe graminis f. sp. hordei. Phys. Mol. Plant Pathol. 49:201-211.

Frick, F., and Wolf, G. 1994. Hydrolytic enzymes of ungerminated and germinated conidia of Erysiphe graminis DC f. sp. hordei Marchal. J. Phytopathol. 140:1-10.

Giese, H., Hippe-Sanwald, S., Somerville, S., and Waller, J. 1997. Erysiphe graminis. Pages 55-74 in: The Mycota, Vol. V-Part B. G. C. Carroll and P. Tudzynski, eds. Springer-Verlag, Berlin.

Gold, S., Duncan, G., Barrett, K., and Kronstad, J. 1994. cAMP regulates morphogenesis in the fungal pathogen Ustilago maydis. Genes Dev. 8:2805-2816.

Hall, A. A., Bindslev, L., Rouster, J., Rasmussen, S., Oliver, R. P., and Gurr, S. J. 1999. Involvement of cAMP and protein kinase A in conidial differentiation by Erysiphe graminis f. sp. hordei. Mol. PlantMicrobe Interact. 12:960-968.

Howard, R. J., Ferrari, M. A., Roach, D. H., and Money, N. P. 1991. Penetration of hard substrates by a fungus employing enormous turgor pressure. Proc. Natl. Acad. Sci. U.S.A. 88:11281-11284.

Kang, S. H., Khang, C. H., and Lee, Y.-H. 1999. Regulation of cAMPdependent protein kinase during appressorium formation in Magnaporthe grisea. FEMS (Fed. Eur. Microbiol. Soc.) Microbiol. Lett. 170:419-423.

Kershaw, M. J., Wakley, G., and Talbot, N. T. 1998. Complementation of the mpgl phenotype in Magnaporthe grisea reveals functional relationships between fungal hydrophobins. EMBO (Eur. Mol. Biol. Organ.) J. 17:3838-3849.

Kinane, J., Dalvin, S., Bindslev, L., Hall, A., Gurr, S., and Oliver, R. 2000. Evidence that the cAMP pathway controls emergence of both primary and appressorial germ tubes of barley powdery mildew. Mol. Plant-Microbe Interact. 13:494-502.

Kunoh, H. 1982. Primary germ tubes of Erysiphe conidia. Pages 45-54 
in: Plant Infection: The Physiological and Biochemical Basis. Japan Science Society Press, Tokyo.

Lee, Y., and Dean, R. 1993. cAMP regulates infection structure formation in the plant pathogenic fungus Magnaporthe grisea. Plant Cell 5:693-700

Lev, S., Sharon, A., Hadar, R., Ma, H., and Horwitz, B. A. 1999. A mitogen-activated protein kinase of the corn leaf smut Cochliobolus heterostrophus is involved in conidiation, appressorium formation, and pathogenicity: Diverse roles for mitogen-activated protein kinase homologs in foliar pathogens. Proc. Natl. Acad. Sci. U.S.A. 96:1354213547.

Mitchell, T., and Dean, R. 1995. The cAMP-dependent protein kinase catalytic subunit is required for appressorium formation and pathogenesis by the rice blast fungus Magnaporthe grisea. Plant Cell 7:1869-1878

Parry, D. 1990. Plant Pathology. Cambridge University Press, Cambridge, U.K.

Sambrook, J., Fritsch, E., and Maniatis, T. 1989. Molecular Cloning: A Laboratory Manual, 2nd ed. Cold Spring Harbor Laboratory, Cold Spring Harbor, NY, U.S.A.

Sanger, F., Nicklen, S., and Coulson, A. R. 1977. DNA sequencing with chain-terminating inhibitors. Proc. Natl. Acad. Sci. U.S.A. 74:54635467.

Sweigard, J. A., Carroll, A. M., Farrall, L., Chumley, F. G., and Valent, B. 1998. Magnaporthe grisea genes obtained through insertional mutagenesis. Mol. Plant-Microbe Interact. 11:404-412.

Talbot, N. J., Ebbole, D. J., and Hamer, J. E. 1993. Identification and characterization of $M P G 1$, a gene involved in pathogenicity from the rice blast fungus Magnaporthe grisea. Plant Cell 5:1575-1590.

Thevelein, J. M. 1994. Signal transduction in yeast. Yeast 10:1753-1790.

Thines, E., Weber, R., and Talbot, N. J. 2000. MAP kinase and protein kinase A-dependent mobilization of triacylglycerol and glycogen during appressorium turgor generation by Magnaporthe grisea. Plant Cell 12:1703-1718.

Thomas, S. W., Rasmussen, S. W., Glaring, M. A., Rouster, J. A., Christiansen, S. K., and Oliver, R. P. 2001. Gene identification in the obligate fungal pathogen Blumeria graminis by expressed sequence tag analysis. Fungal Genet. Biol. 33:195-211.

Valent, B., Crawford, M. S., Weaver, C. G., and Chumley, F. G. 1986. Genetic studies of fertility and pathogenicity in Magnaporthe grisea. Iowa State J. Res. 60:569-594.

Xu, J.-R., and Hamer, J. E. 1996. MAP kinase and cAMP signaling regulate infection structure formation and pathogenic growth in the rice blast fungus Magnaporthe grisea. Genes Dev. 10:2696-2706.

Xu, J.-R., Urban, M., Sweigard, J. A., and Hamer, J. E. 1997. The CPKA gene of Magnaporthe grisea is essential for appressorial penetration. Mol. Plant-Microbe Interact. 10:187-194.

Yang, Z., and Dickman, M. B. 1997. Regulation of cAMP and cAMP dependent protein kinase during conidial germination and appressorium formation in Colletotrichum trifolii. Phys. Mol. Plant Pathol. 50:117-127.

Yang, Z., and Dickman, M. B. 1999a. Molecular cloning and characterization of $c t-P K A R$, a gene encoding the regulatory subunit of cAMP-dependent protein kinase in Colletotrichum trifolii. Arch. Microbiol. 171:249-256.

Yang, Z., and Dickman, M. B. 1999b. Colletotrichum trifolii mutants disrupted in the catalytic subunit of cAMP-dependent protein kinase are nonpathogenic. Mol. Plant-Microbe Interact. 12:430-439.

\section{AUTHOR-RECOMMENDED INTERNET RESOURCES}

Blumeria genomics database: www.crc.dk/phys/blumeria

Plant protection database (Planteværnsdatabase vedr. plantesygdomme 2000): www.lr.dk/planteinfo/pcp/MeldugVa 